\title{
Learning 2.0: collaborative technologies reshaping learning pathways
}

\author{
Popovici Veronica \\ "Ovidius" University of Constanta \\ Romania
}

\section{Introduction}

The development of the Internet into the highly versatile, dynamic and democratized medium it is today has brought with it incredible transformations and opportunities in practically all fields of human activity. A new set of Internet-based technological tools, all gathered together under the roof of one broad term - Web 2.0 - are describing the increasing use of the Internet as a technology platform to enhance functionality, communication and collaboration. It encompasses the explosion of Web-delivered content, interconnectivity, new applications and social networking. The term "Web 2.0" actually describes the changing trends in the use of World Wide Web technology and web design that aim to enhance creativity, secure information sharing, collaboration and functionality of the web.

Web 2.0 applications like blogs, wikis, online social networking sites, photo- and videosharing sites and virtual worlds have known an exponentially increasing development and popularity over the past few years. Research evidence suggests that these revolutionary online tools have not only had an impact on people's private and professional lives, but have also started to affect large organizations and institutional structures, leading them towards more collaborative and synergetic approaches. This process - intrinsically based upon the latest online technologies - is extremely interesting to observe in the educational sector, as an enhanced efficiency at this level is further on naturally disseminated in all segments and fields of activity.

Moreover, taking into account all the great advantages of using such tools in providing high quality, modern educational services and catalyzing learning processes, we believe this is an extremely interesting topic, of utmost importance for the future of education and the development of generations to come. After all, we are witnessing the dawn of a new era pertaining entirely to "digital natives" (Mason \& Rennie, 2007), as today's children are using Web 2.0 technologies comfortably and efficiently and they will continue to do so ever more naturally. The reason why using these tools in educational settings is so crucial, particularly at this point in time, reveals itself from two different aspects merging together. On one hand, the younger generation will always need help from their older, wiser fellows in order to learn what they need to be successful in the complicated structures of the society they will grow up to be a part of. But, on the other hand, until these digital natives will start becoming those fellows, here we are still the representatives of those few "transition" 
generations in different stages of technical ability that are bound to adapt quickly to the imminent trends and find efficient measures to support imposing multiple innovations of the educational system, that will eventually permit a functional blend between the "old" and "new" tools and patterns for learning, as well as a smooth evolution of the entire system.

Bringing together the two realms of Web 2.0 and learning, in any form or type of organization around the globe, we will address the phenomenon under discussion with the term of "Learning $2.0^{\prime \prime}$, as it already appears in a few pioneering research papers. Since the concept of collaborative technologies is only a few years old itself, discussions around the topic of its fusion with the educational sector are an even bigger novelty. Therefore research on Learning 2.0 is still scarce, the only comprehensive project in this area of study, apart from some disparate articles and studies on different, very restricted aspects of Learning 2.0, being one initiated by the Institute for Prospective Technological Studies (IPTS) and the European Commission Directorate Education and Culture (DG EAC) in 2008. "Learning 2.0 the Impact of Web 2.0 Innovations on Education and Training in Europe" (Redecker et all, 2009) aims at gathering concrete evidence on the take up of social computing by European education and training institutions, to understand its impact on innovations in educational practices and its potential for a more inclusive European knowledge society. At the same time, this research project also envisioned identifying challenges and bottlenecks so as to devise policy options for European decision makers, all in all proposing a very complex approach to understanding the role of collaborative technologies in European education and training institutions.

Although the final report issued at the end of this study is a very important informative tool for anyone plunging into this field, there are two disadvantages entailed. First of all, the results are biased by concentrating only on European institutions, which although was one of the major premises of the project, nevertheless cannot be ignored as a restrictive feature, and second of all our entire discussion takes place on very rapidly changing grounds, the Web 2.0 movement having suffered tremendous developments during the last couple of years. Having pointed out so far only the main limitations of this front-runner contribution in the Learning 2.0 field, we would like to mention a couple of other aspects that could be added into the same category. In our opinion, this study focuses primarily upon organizational innovation measures that need to be implemented in order to assure the efficiency of Web 2.0 tools within education and training institutions, in the detriment of other key aspects of the analyzed issue. One of these could consist into the main advantages of using Web 2.0 tools in educational contexts (such as their crucial contribution in distance education, informal learning and decoding tacit knowledge, as well as in the process of developing essential character and personality treats of future citizens of the world), which we believe it is a noticeably underdeveloped aspect in this study and also one that we will try to enrich with our research endeavours.

This is why, building upon existent research, we are proposing a more general, up-to-date and logically structured overview of the Learning 2.0 field, in which we intend to emphasize all the fundamental advantages of Learning 2.0 practices and the most severe challenges laying ahead for them. Our hopes are high that a clear outline of this phenomenon and its determining landmarks - one of the priority goals of this chapter - will foster deeper interest and further research into this very lively and current topic.

In order to reach this we will begin with a detailed exposure of the Internet's development into what it has become nowadays, providing also a general view of the web-based tools 
accountable for its nomenclature. The purpose of all this will be to sketch the basic context in which we will take a deeper look at the multiple ways of Web 2.0 applications transforming learning patterns and pathways, or more exactly at all the advantages, opportunities and challenges brought by using such technologies for learning and at the ways in which current structures must metamorphose in order to best accommodate the positive aspects, while eliminating the negative ones.

\section{The development of the Internet into Web 2.0}

We would not be able to talk about innovative collaboration technologies nowadays without having witnessed over the past few decades one of the most influential global scale phenomenon, that will have definitively reshaped the history of human kind - the rise of the Internet. According to official statistics, the growth of the World Wide Web in terms of number of users and their interconnected networks has been exponential for almost two decades. ${ }^{1}$

The reach of the Internet is global - although it began in the US and is unquestionably a western technology, its presence and growth is no longer limited to western cultures. In fact, highest growth rates are registered in other regions such as Africa, the Middle East and Latin America, all of which points out to a more and more interconnected world. And the rationale behind this continuously increased interconnectedness is nothing else but the omnipresent ambition of overcoming geographic distances as primary barriers to information and knowledge access at a global scale.

The incredible growth rate of the Internet in such a short period of time has also made it evolve into a more user-friendly medium, which allows us to define it today according to both a technical and a social model. Therefore, the major impact of its growth may not be in the connectivity itself (which is significant, as mentioned above), but in the secondary changes in behaviour and values that such connectivity seems to stimulate (Mason and Hart, 2007).

The emerging technical model means that the evolutionary development of web technology enables new capabilities for users. Higher bandwidths mean that images and videos are more readily available, thus increasing the richness of the media accessible on the web. Additionally, users can label, or "tag" pages and information units. Consequently, the web becomes increasingly dense in terms of primary content (the text web pages, the images and the video), the metadata of tags, and the linkages among sites and pages. Collectively, all three (primary content, metadata, and linkages) create a set of extraordinarily rich sources of information, so that becoming aware of the combination of the three dimensions presents opportunities for learning and for innovative connections among previously unrelated assemblages of facts and relationships (Mason and Hart, 2007).

The emerging social model is enabled by how people choose to use the evolving technical capabilities. These permit and even encourage the formation of new social networks focused on particular interests or other shared characteristics, ranging from such simple concepts as attending the same school to more complex associations such as a shared interest in particular types of books or hobbies.

The significance of these examples of Internet deployment - one oriented toward software development, one purely social - suggests that what we are seeing is a new approach to using the giant network. It has become the meeting space - a virtual "third space" for

${ }^{1}$ http:/ / www.internetworldstats.com/stats.htm 
gathering, beyond the physical ones like the workplace and the home - that goes beyond simply searching for and accessing information. The Internet is changing how we interact with each other, if it's either for learning from each other, for working together or for new ways of recreation. What it does is actually gathering a wide range of intertwined advanced and emerging technologies into the so-called second phase of the evolution of the online world. This is also the reason why the term "Web 2.0" has become so popular for defining these new technologies of the Internet, representing - as shown above - only the suggestion of an upgraded network, of an Internet naturally developed into a new stage of existence and functionality.

According to Tim O'Reilly (2005), the one who introduced this term, Web 2.0 is the business revolution in the computer industry caused by the move to the Internet as a platform, and an attempt to understand the rules for success on that new platform. O'Reilly said that the " 2.0 " refers to the historical context of web businesses "coming back" after the 2001 collapse of the dot-com bubble, in addition to the distinguishing characteristics of the projects that survived the bust or thrived thereafter. The Internet era prior to that, the one pertaining to web developers and specialists only, is known as the Web 1.0 period, while Web 2.0 is what we call the democratized Internet or the Internet for everybody, since anyone in the world can easily go online and create their own contents there.

What stays behind this empowerment of the masses, of this engagement in mass participation is the fact that all the Web 2.0 technologies under the loop here make it almost effortless for individuals to contribute to the web based discussion and provide an extremely convenient support for social interaction and exchange of one form or another. Since these tools have transformed the Internet into a place for networking, community building and sharing collective experience, some have been led to describe this new phenomenon of massively distributed collective intelligence as "the wisdom of crowds" (Ballantyne \& Quinn, 2006), giving a first hint towards the bigger idea developed throughout this chapter of people sharing knowledge, learning together and exploring new ways of capturing and disseminating their intelligence, all processes enabled by innovative technologies of the Internet.

To enter more concretely into the world of Web 2.0 tools and paint a fairly comprehensive picture of these technologies without making use of an excessively technical vocabulary, here are the most popular ones of these tools and what they capture in essence:

- Weblogs or blogs are freeform digital canvases used to communicate in an open setting or well-defined group to capture topic-specific content in the form of articles (posts) listed in reversed chronological order; blogs can encompass all sorts of content, from visual, audio and video, as well as links to other blogs, information about the author and readers' comments; the term blogosphere has been born with the explosion of blogs around the world - there are currently around 100.000 new blogs created daily (Pascu, 2008) - describing the online world of these public writing environments;

- Wikis are web-based tools designed for collaborative, unstructured interactions among formal and informal groups, popular with project teams for coordinating work, team editing and capturing project updates; the most well-known example of a wiki is Wikipedia, a collaboratively-created online encyclopaedia with more than 75000 active contributors working on more than 10 million articles in 250 languages (http://wikipedia.org/). 
- Tagging, social bookmarking and folksonomies represent basically assigning categories/names to Web and other content, such as articles, books (Amazon), pictures (Flickr), videos (YouTube), blogs (Technorati) and wiki entries, or institutional and team documents;

- Social networking/online communities refer to Web-based sites or internal platforms that supports interaction among users of all kinds;

- Social filtering means letting users rate content to create collective opinion of its relevance and value;

- Mash-ups are the result of combining data from two applications (usually with open application programming interfaces) that weren't originally intended to work together.

- Virtual worlds are nothing else but virtual environments like Second Life or similar online 3D virtual worlds where users can socialize, connect and create using free voice and text chat.

All of these tools and others have slowly made their way into most every aspect of human life. We use them to stay connected with each other, to work more efficiently, to extend our network of peers, to enhance marketing and management activities and basically to share everything - from personal to field-specific information, from comments and opinions to institutional knowledge. Further on we are going to see how they are used also in enabling learning processes - formal or informal - what are the premises for such innovations in the realm of education and what amazing opportunities they bring along from this very specific and interesting point of view.

\section{From Web 2.0 to Learning 2.0}

Having a fairly clear image about some of the most largely used Web 2.0 tools and how the Internet developed into incorporating such innovative technologies, we can now reach the nucleus of our endeavour and address their role in learning and educative processes. We are basically referring to emerging initiatives of integrating Web 2.0 applications in educational contexts, a phenomenon unsurprisingly labelled as Learning 2.0. As it was mentioned before, there have been a lot of discussions about the effect that web technologies are having on commerce, media and business in general but a much more little coverage on the impact they are having on education. Like the web itself, technology enabled learning processes have gone through profound transformations as well. It actually all started with e-learning, comprising all forms of electronically supported learning and teaching, content being delivered via the Internet, intranet/extranet, audio or video tape, satellite TV, and CD-ROM, enabling the transfer of skills and knowledge.

The early promise of e-learning though - that of empowerment - has not been fully realized, as for many the experience of e-learning has been no more than a hand-out published online, coupled with a simple multiple-choice quiz, which is hardly inspiring, let alone empowering. This happened because the traditional approach to e-learning has been to employ the use of a Virtual Learning Environment (VLE), software that is often cumbersome and expensive - and which tends to be structured around courses, timetables, and testing (Becta, 2007). 
This is an approach that is too often driven by the needs of the institution rather than the individual learner.

Teachers sensed this major flaw of e-learning materials and have started to explore the potential of blogs, media-sharing services and other social software - which, although not designed specifically for e-learning, can be used to empower students and create exciting new learning opportunities. And these is how, by using this new web services, e-learning has tapped into its potential of becoming far more personal, sociable and flexible - in other words, of becoming Learning 2.0. One of the pioneers that intuitively recognized the beginning of this transition is Stephen Downes ${ }^{2}$, a senior researcher with the National Research Council of Canada based in Moncton, New Brunswick at the Institute for Information Technology's e-Learning Research Group, who firstly coined the phenomenon as e-learning 2.0 and described it as an approach that combines the use of discrete but complementary tools and web services such as blogs, wikis, and other social software to support the creation of ad-hoc learning communities.

In order to better understand how this happens specifically, we are further on going to look into the use of each of the major Web 2.0 tools in part for educational purposes.

We are going to start with blogs, as they are very easy and flexible tools for using, with various educational advantages, as shown by the increasing number of research studies in their educational usage. Blogs not only remove the technical barriers to writing and publishing online, but the "journal“ format encourages students to keep a record of their thinking over time. Blogs of course also facilitate critical feedback, by letting readers add comments, which could be from teachers, peers or a wider audience. So it is suggested that blogs enhance writing skills, facilitate reflection, encourage critical thinking with collaborative learning, and provide feedback and active learning (Ellison \& Wu, 2008). Blogs are well suited to serve as online personal journals because they enable students sharing files and resources, giving them the possibility of writing for readers beyond their classmates (Bruns, 2008). In addition, blogs can be used as e-portfolios that keep records of personal development process, reflections and achievement (Alexander, 2007). The beauty of it is that a blog needn't be limited to a single author - it can mix different kinds of voices, including fellow students, teachers and mentors, or subject specialists (experts of the dicussed matter or even personalities of the world outside immediate education circles, such as authors of studied novels or creators of studied art pieces), becoming a very interactive medium for learning with all these different peers being able to bring their input on a specific curricular subject in a certain virtual space.

As blogs, wikis have also attracted attention in educational field for their advantages and usability, and studies about using wikis in education have increased in number. Wikis are considered to be effective tools for learning and teaching as they facilitate collaborative learning, provide collaborative writing, support project based learning, promote creativity, encourage critical searching, support inquiry based and social constructivist learning (Konieczny, 2007). Some of other educational usage of wikis are also suggested as classroom websites, easy course administration and timetabling, easy online updating content, online dictionary, student feedback and self assessment, bibliographically organized class or group projects, virtual classes for online collaboration, creating frequently asked questions (FAQ) for classroom or students (Augar et all, 2004; Konieczny, 2007).

${ }^{2}$ http://www.downes.ca/news/OLDaily.htm 
Podcasting has aslo become a popular technology in education, in part because it provides a way of pushing educational content to learners. For example, Stanford University has teamed up with Apple to create the Stanford iTunes University ${ }^{3}$, which provides a range of digital content (some closed and some publicly accessible) that students can subscribe to using Apple's iTunes software. Especially as podcasting is being used with mobile devices, it can be viewed as another variant of mobile learning. Although podcasting is not a synchronous activity, it provides students information that will help them feel connected to the learning community. Moreover, as with blogging, podcasting provides students with a sense of audience - and they are highly motivated to podcast because the skills required seem relevant to today's world (Lee et all, 2008).

Social networks can also be viewed as pedagogical tools that stem from their affordances of information discovery and sharing, attracting and supporting networks of people and facilitating connections between them, engaging users in informal learning and creative, expressive forms of behaviour and identity seeking.

Even media sharing sites like Flickr or YouTube have found their use within education. Flickr provides a valuable resource for students and educators looking for images for use in presentations, learning materials or coursework, and the tagging of images makes it much easier to find relevant content. Just as well, YouTube can be used in several interactive assignments where the final result can be viewed/appreciated/commented on in video format online by classmates and the wider YouTube community.

So far we have managed to get only a brief glance into the use of Web 2.0 tool for education and learning, the topic being enriched with new practical examples or best practices every day. At the same pace increase also the research efforts of studying the impact of each and every one of these new media in educational contexts, which is a gratifying thing, bringing us more and more evidence of Web 2.0 technologies clearly reshaping learning pathways at the moment. To quickly summarise all of the above, being slowly introduced also in the educational system, such applications:

- facilitate access to information for everyone, making institutional processes more transparent and the distribution of educational material more efficient;

- integrate learning into a wider community, reaching out to virtually meet people from other age-groups and socio-cultural backgrounds, linking to experts, researchers or practitioners in a certain field of study and thus opening up alternative channels for gaining knowledge and enhancing skills;

- support the exchange of knowledge and material and facilitate community building and collaboration among learners and teachers;

- increase academic achievement with the help of motivating, personalised and engaging learning tools and environments;

- implement pedagogical strategies intended to support, facilitate, enhance and improve learning processes (Redecker et all, 2009).

Thus, such emerging technologies and changing pedagogies bring out the necessity for more effective two way communication, promoting interaction and collaborative working,

${ }^{3}$ http:/ /itunes.stanford.edu/ 
sharing and flexible participation between all participants in the education and learning environment. We can honestly say now that we understand the Learning 2.0 phenomenon as one of utmost importance and actuality, announcing what might become a crucial impact on the future of educational pathways worldwide. Bearing this acknowledgement in mind, we will further embark on an attempt to better grasping the implications of Learning 2.0 developments, by underlining the core positive aspects they bring in, as well as the biggest challenges and bottlenecks.

\section{Discussing Learning 2.0}

\subsection{Opportunities and advantages}

The most obvious advantage of using Web 2.0 tools within educational and training contexts of all kind would be their contribution in terms of fostering worldwide innovation and modernization of this field. As the already undertaken research suggests and as the figure below very clearly depicts, Learning 2.0 strategies would contribute in particular to three dimensions of innovation - technological, pedagogical and organizational innovation.

The self-explanatory matrix in Figure 1 pictures the way in which Learning 2.0 strategies bring together several core aspects of our lives, providing the technological premises (new ways, tools and methods) for learning, then drawing the attention upon the basic need of organizational transformations (re-creating teaching and learning practice), so that in the end all the preconditions are there for pedagogical innovation and empowerment of the learner.

Establishing this incremental pace, Learning 2.0 strategies first of all imply the existence and usability of collaborative technologies, that would increase the accessibility and availability of learning content and would of course provide new, more efficient frameworks for knowledge acquisition, dissemination and management. Building on our introductory arguments, Web 2.0 tools allow embedding learning activities in more engaging multimedia environments, with a high degree of quality and interoperability, where dynamic or individualised learning resources are easily created. Moreover, the simple fact that Learning 2.0 helps overcoming the limitations of face-to-face instruction through versatile tools for knowledge exchange and collaboration is a great achievement per se and something that could be made the most of in remote areas where there is an unbalanced ratio between the number of learners and available teachers.

Moving forward to the next innovation dimension, namely the organizational innovation, Learning 2.0 both requires and promotes this type of transformations and it can contribute to making educational organisations more dynamic, flexible and open. Through collaborative technologies institutions in this sector can become reflective organisations that critically evaluate and revise their corporate strategies in order to support innovative pedagogies. But in order for this to happen first of all the necessary infrastructure in which social media tools are accessible to all learners and teachers needs to be provided. In addition to this, educational institutions need to make efforts towards creating an atmosphere of support for Learning 2.0, in which new teaching and learning models are fostered and new assessment and grading strategies are integrated. 


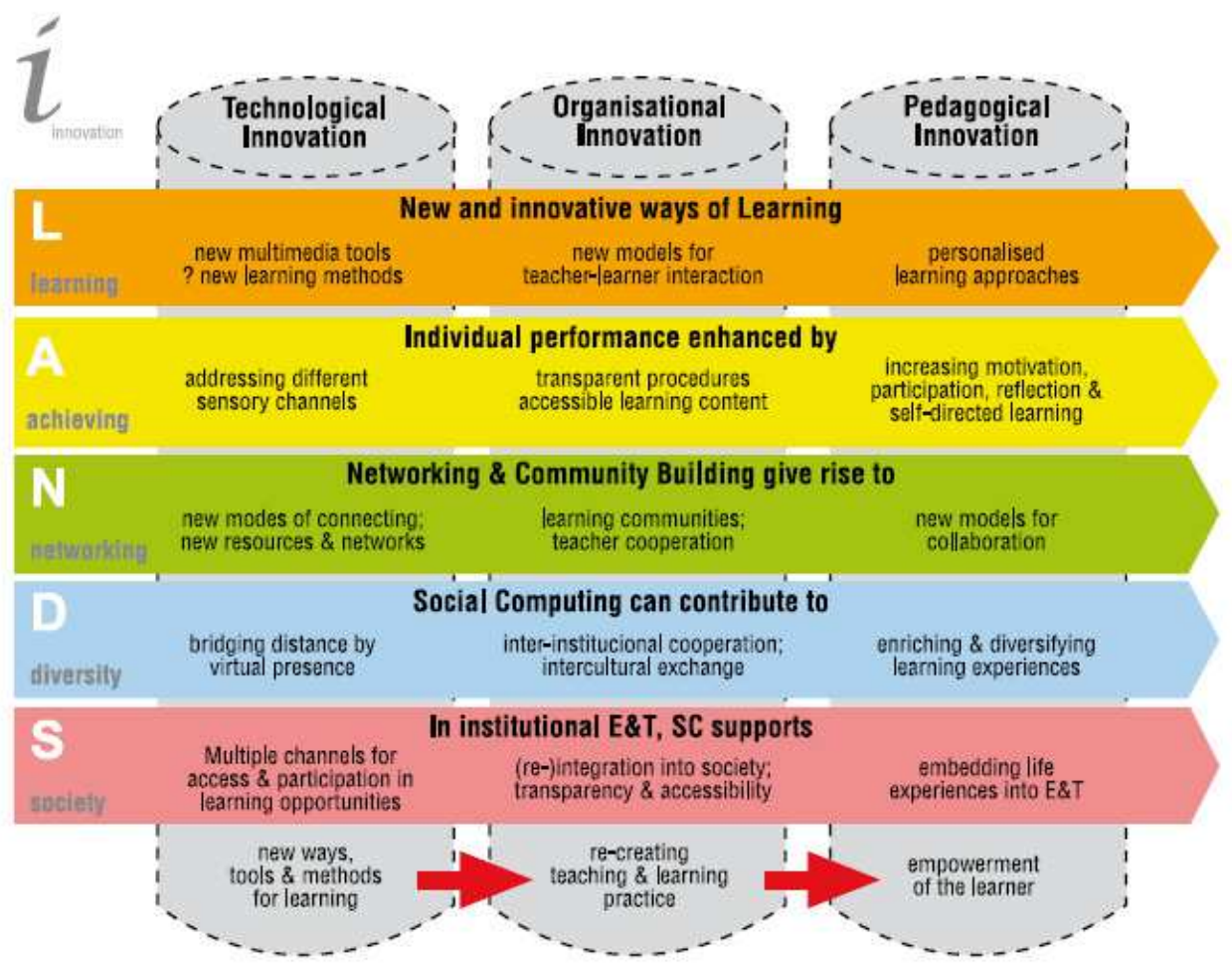

Fig. 1. Te innovative potential of Learning $2.0^{4}$

Once all these developments are mobilized, the primary sine-qua-non conditions are set for learning approaches using social media to promote pedagogical innovation, which basically presumes encouraging teaching and learning processes that are based on personalisation and collaboration. The main consequence of pedagogical innovation lays in a redefining shift within interaction patterns between and among students and teachers. This way teachers become much more than just instructors or lecturers - they embrace their roles as coordinators, moderators, mediators and mentors. At the same time students' roles evolve as well, from taking responsibility for their own learning progress to also having to support each other in their learning endeavours, and jointly creating the learning content and context. Hence, Learning 2.0 offers the entire playfield where learners can and are encouraged to assume a pro-active role in the learning process and develop their own individual and collective - rules and strategies for learning.

Much more than just enhancing innovation at these three interrelated levels, social media support engages playful approaches, provides new formats for creative expression and encourages learners and teachers to experiment with different, innovative ways of articulating their thoughts and ideas. The Learning 2.0 landscape itself is shaped by experimentation, collaboration and empowerment, and allows learners and teachers to discover new ways of

${ }^{4}$ Source: Redecker et all (2009), page 45 
actively and creatively developing their individual competences, which in turn provides a rich soil where further innovation and quality learning can flourish.

Taking all this into consideration and the general fact demonstrated so far that emerging technology plays a key role especially for promoting interaction, delivering education and providing communication between individuals, we turn now to the crucial role of Learning 2.0 strategies in distance education. Several studies underlined the significance of interaction and the actual necessity of several interaction forms like student-teacher, student-student, studentcontent etc., contributing to the feeling of quality learning in distance education in particular. Many research studies reveal technology perceived as an enabler and intensifier of interaction, which leads at its turn to satisfaction of students, eliminating isolation feeling and effective learning outcomes (Chang et all, 2008; Cramer et all, 2007). Usluel \& Mazman (2009) explained that distance learning systems use technology to separate learner from the teacher and learning group while maintaining the integrity of education process and attempting to replace the interpersonal communication and the inter subjectivity which is the essence of education transaction between teachers and learners, by a personal form of communication mediated by technology. Interaction in distance education is not limited to audio and video, or solely to teacher-student interactions, it must also represent the connectivity, the students' feel with the distance teacher, aides, peers etc., otherwise without interaction students become autonomous, isolated and procrastinate and drop out (Usluel \& Mazman, 2009).

Therefore we can observe emerging technologies bringing out the necessity for more effective two way communication, promoting interaction and collaborative working, sharing and flexible participation, and also supporting the transition towards a distance learning system dominated by all these positive aspects. Moreover, emerging technologies not only have an impact on new ways of learning in distance education, but also on new models of teaching (Rennie \& Mason, 2004). It is suggested that by the interactive technologies and medias which are provided by Web 2.0, these new pedagogic approaches that imply a closer relationship with students through active participation and effective twoways communication on virtual open platforms such as blogs or wikis are also supported.

Considering distance education in very broad terms, everything we brought into discussion above is actually an only natural development in the field of education in general, following similar systematic developments in other domains as well. If we think about the many ways in which all sorts of human activities between peers situated in geographically dispersed locations have been enabled by new technologies of the Internet, we can definitely say it was only a matter of time before these technologies began to be widely utilised in long distance education. Web 2.0 tools improve the quality of the pedagogical act in such contexts, supporting it in interactive and multivalent environments, and offering a wide palette of applications to display learning content and materials, projects and assignments, groupwork and examinations, which will all enrich the experience of learners engaged in long distance education by making the entire process more lively, dynamic and engaging. Beyond this, Web 2.0 technologies offer the learner itself a vast array of supports for expression and exercise of the learned content, which highly upgrade its level of preparation before examinations. If before such tools were introduced long distance students were usually "served" course materials on a certain static online location where they would access it, accumulate it and then deliver it within organized examination sessions, things are totally different now, with the new media hosting all sorts of applications whose role is to make the course materials more accessible and to help students better understand the 
practical utilization of what they are learning, while also serving as support for various types of projects and assignments.

But this type of increased interaction and versatility that emerging technologies are praised for bringing into the field of distance education are also the reason why Web 2.0's advantages should be considered on a much larger scale. Around the world people engage in learning activities that are not necessarily structured or organized in any way, but appear as a natural flow of continuously modulated information, made available on the web by millions and millions of peers following their passions, interests, fears, uncertainties, etc. and tapping into the "wisdom of crowds" they end up enriching themselves. What we are basically referring to is the concept of informal learning, involving all that is learned throughout life in the day-to-day processes at home, work and leisure; and since Web 2.0 applications have slowly found their place into all of these settings it seems only obvious to reflect upon their role in informal learning activities, of whose importance is largely underestimated, but who contribute to our pool of reliable facts and experiences much more than we even imagine. The acceptance of informal learning acknowledges that there is more to learning than the absorption of "explicit" knowledge codified in texts and delivered during formal courses. It also, crucially, consists of access to "tacit" or implicit knowledge, which is exactly what all sorts of social media have best to offer. Therefore, when considering the main benefits of user-generated-content fuelling the brought up "wisdom of crowds" phenomenon, one of the most obvious one would be the fact that users have a lot of tools at their disposal to join the global conversation and actively engage in the construction of their (learning) experience, rather than merely absorb content passively. And this content will be constantly refreshed by the users, it will not require expensive expert input, something which accentuates both its purely authentic character and its reliability, the democratic nature of the web making sure that every piece of information, data or statement out there can be reinforced or refuted by users with similar experiences/authorized opinions and various ways of expression at their disposal.

All in all, through the broad variety of versatile tools, social media or Web 2.0 in general allows the implementation of more effective learning strategies that can furthermore improve individual performance, actively foster the development of transversal competences, and nurture abilities to flexibly develop skills in a lifelong learning continuum. This is easily attainable because the Learning 2.0 spectrum offers accessible, flexible and dynamic learning environments that can complement and supplement initial training. Furthermore, the networking potential of social media, together with its power to overcome time and space barriers, supports interaction and collaboration among and between learners and teachers who are geographically dispersed and enables students to broaden their horizons, and collaborate across borders, language barriers, and institutional walls. Hence, team-work abilities are highly developed by collaborative work environments supported by most of the Web 2.0 tools like shared community spaces and inter-group communication platforms, which are also a massive part of what excites young people and therefore should contribute to users' persistence and motivation to learn.

Last but not least, research results indicate that social media approaches to learning can mitigate existing inequalities and can be employed to successfully re-engage individuals who are at risk of exclusion from the knowledge society. Learning 2.0 strategies can thus effectively increase the accessibility and availability of learning opportunities for the hard to reach, and can significantly improve motivation and engagement in learning. 


\subsection{Challenges and bottlenecks}

While the potential of social media for enhancing learning opportunities is substantial, there are nevertheless a few obstacles to the smooth implementation of Learning 2.0 strategies. The first one we need to mention is the very basic premise for collaborative technologies becoming a part of any process: Internet access. Although the number of people going online has increased tremendously during the past few years, the Internet is still not a commodity everywhere, in some parts of the world being actually very far from that. So then we ask ourselves how can we talk about the blessings of Learning 2.0 in a democratic way when access to such practices is prohibited sometimes due to disparities in economic and technical development.

Apart from the still non-unanimous use of Internet nowadays that will hopefully soon be overcome, we can identify further technical, organizational and pedagogical bottlenecks that hinder the fast spread and efficacy of Learning 2.0 practices. More than the lack of proper facilities allowing access to internet communication technologies in all educational institutions, access to basic digital skills constitute a major obstacle for the use of social media in education activities, and a key problem for inclusion and equality. In this sense both learners and teachers face a challenge - teachers in particular as they do not feel confident enough with their information and communication technology skills to experiment with Learning 2.0 strategies and further on they also need assistance sometimes, when their students don't have advanced digital competences, in supplying them with the necessary digital skills to safely use social media environments. Especially in this case, the mainstream deployment of Learning 2.0 approaches and strategies might be hindered by a lack of didactic methodologies, toolsets and training programmes for teachers which would also enable them to assume their new role as guides and mentors.

Another very important aspect when considering social media in educational institutions is the safety and privacy concern. Learning 2.0 strategies require the confident and critical use of these tools and an informed and critical attitude towards interactive media and digital information (Hulme, 2009). Constantly bearing this in mind is an extra responsibility that needs to be assumed by educators, who have to make sure that the identities of their learners are protected; that rules of conduct are implemented and adhered to; and that intellectual property rights are respected.

Learning 2.0 brings requirements also on institutional change, as with their rooting in formal education processes comes also a re-evaluation of educational institutions' role in society as knowledge providers. This challenges rigid existing power structures, as resistance to change limits the development of new concrete ways to support teachers, learner and administrators and generally encumber these institutions when it comes to taking an active role in deploying promising Learning 2.0 strategies. And in order to offer a very objective depiction of this situation, it is sadly accentuated by the tumultuous character of social media landscape, which underlies continuous change and transformation and hence a lot of uncertainty concerning the future development and availability of current applications and services, the reliability of user-produced content, suitable assessment and certification strategies; and valid pedagogical concepts and methods for learning with social media.

Strongly related to this aspect appears the fact that, although it is easy to see the Web 2.0 environment as an extension or development of pre-existing tools and approaches for learning, there are however some critics of these tools and user-generated content in general 
that refer to a break-down in the traditional place of expertise, authority and scholarly input. They express concerns about trust, reliability and believability in relation to the move away from the printed word to the more ephemeral digital word. Furthermore, if content is created by users on different systems like podcasts, blogs, wikis, chat systems, and other social networking software, then it can be difficult to keep track of where everything is, and to access it with ease, both for those that use that content in formally structured learning frameworks and the casual visitor in search for informal learning fruits. This in turn calls for new tools to help users search and integrate across content that may be quite fragmented, a concern which is slowly but surely addressed through the proliferation of other innovative tools such as tagging, folksonomies and others.

Last but not least, we must not forget that the great uses of Web 2.0 tools for learning are not guaranteed without the users' interest in such technologies and what they have to offer. And although there is a general consensus that at least the new generation of learners are all about collaborative technologies and social media, their attention and dedication to these tools might not always be constant. This can have serious consequences on the success of Web 2.0 applications, which is strongly dependent upon the users being regularly connected and contributing to the shared content on these platforms. Thus, there is a real need to understand the dynamics of the attention-grabbing effect of Web 2.0 and harness it for education purposes.

\section{Conclusion}

There is no doubt that new information and communication technologies become a more and more important part of our lives as we speak, reaching up to every layer of our existence. With the continuous globalization of information, learning independent from time, place, cost and other needs begins to make use of innovative Web 2.0 technologies, spreading an air of freshness and imminent transformations among old systems and learning patterns and determining a reassessment of their constitutive structures in order to better accommodate envisioned advantages of the new media.

This chapter focused on the influence of such tools in the educational field as an emerging worldwide trend, endeavouring an objective depiction of pros and cons when considering the integration of social media within current conservative teaching and learning patterns. Departing from a historical approach upon the development of the internet into the socalled Web 2.0 social networking environment it has become nowadays, we are relating these innovative tools to educational practices and styles, trying to understand the emerging phenomenon of Learning 2.0 with the opportunities and challenges it brings for learner and education systems and structures worldwide.

Social media applications provide easy, fast and efficient ways to access a great diversity of information and situated knowledge. To quote Tiwana (2002), "knowledge is one of the few resources that demonstrates increasing returns to scale: the more you share it, the more it grows". Then it is only logical, if knowledge dissemination lays at the core of its thriving, that we should do everything standing in our power to stimulate and support the transfer of knowledge among as many individuals as possible even from our instruction years, offering ourselves the perfect tool for effectively building competences in collaboration with other learners, practitioners and stakeholders in a lifelong continuum. The technological development has brought us as far as being constant parts of an online, digital, parallel 
universe, with new, improved and easy to use applications, making the Internet maybe the most democratic space of all and the entire mankind a co-generating part of it. So why not use this "universe" to stimulate and support core learning processes, why not tap into all the advantages and opportunities Web 2.0 tools bring in the education field, why not let them facilitate for all of us the development of key competences for the 21st century?

Learning 2.0 encompasses after all the modern tools needed for appealing to a whole new generation of learners - the "digital natives" who absorb information quickly, in images and video as well as text, from multiple sources simultaneously, they operate at very fast speed, expecting instant responses and feedback, they prefer random "on-demand" access to media, expect to be in constant communication with their friends (who may be next door or around the world), and they are as likely to create their own media (or download someone else's) as to purchase a book or a CD (Tapscott, 2009). Using Web 2.0 applications in educational processes involving this new generation of learners is speaking their own language when preparing them for life and therefore becoming more efficient at it.

As we have shown throughout this chapter, Learning 2.0 represents also the development of e-learning applications, which begin to look much more like a blogging tool (viwed as a node in a web of content, connected to other nodes and content creation services used by other students), a personal learning center (where content is reused and remixed according to the student's own needs and interests) or like a personal portfolio tool. The idea here is that students will have their own personal place to create and showcase their own work. The portfolio can provide an opportunity to demonstrate one's ability to collect, organize, interpret and reflect on documents and sources of information. It is also a tool for continuing professional development, encouraging individuals to take responsibility for and demonstrate the results of their own learning. All of these new tools and opportunities for learning and developing young people have today constitute much more than a system of education - they shape an entire environment for flourishing learning. We say this because, in comparison to the very rigid demarcations of the classical education system before the smooth adoption of Web 2.0 tools, this new environment recognizes that the learning comes not from the design of learning content but from how it is used.

Slowly and surely more and more people among which learners, trainers, pedagogs and members of the academia begin to acknowledge these facts and dedicate research resources towards the better understanding of these intrinsic transformations in the education field, of their premises, consequences and influencing factors in order to harness the potential of Learning 2.0. In this sense, a great amount of work is being done, for example, in educational gaming and simulations. Although a rather new practice, several universities around the world have already a few years experience with such Web 2.0 enabled educational simulation programs, convinced by their promise to foster interaction and team-work abilities, increase active participation, assuming responsibility and gaining experience in a profesional simulated environment, as well as the opportunity to develop distance education and inter-institutional projects. Being actively involved in the development and derulation of a business simulation research project with participants from several Romanian universities, a personal appreciation of these type of programs would go directly to saying that the most important learning skills one sees children getting from such games and simulations are those that support the empowering sense of taking charge of their own learning. And the learner taking charge of learning is antithetical to the dominant ideology of a curriculum design, which is more than enough to understand why these developments are tremendously important in the field of education and why more and more 
efforts should be dedicated towards a more recurrent and efficient implementation of innovative tools of all kinds in various edicational contexts. One of such contexts would be also the realm of mobile learning, a rapidly rising domain, that offers not only new opportunities to create but also to connect, by defining new relationships and behaviours among learners, information, personal computing devices and the world at large (Wagner, 2005).

To sum up, the already undertaken research points out that there is not only a great potential of innovation at a technical, organizational and pedagogical level brought in by Learning 2.0 strategies, but that there are also several obstacles rising up in front of the social media efficacy in education institutions. There are indeed great arguments in favour of their adoption, like the fact that they allow learners to access a vast variety of (often freely available) learning content, which supports incessant learning and professional development even in informal settings, it enables distance education accentuating the interaction and motivation for learning, it contributes to equity and inclusion and puts pressure on education institutions to improve the quality and availability of their learning material. Moreover, since social media allow users to create digital content themselves and publish it online, it gives rise to a huge resource of user-generated content from which learners and teachers can mutually benefit, also encouraging more active and pro-active approaches to learning. Last but not least, it connects learners with one another, experts and teachers alike, allowing them to tap into the tacit knowledge of their peers and have access to highly specific and targeted knowledge in a given field of interest, at the same time supporting also the collaboration between them on a given project or a joint topic of interest, pooling resources, creating synergies and gathering the expertise and potential of a group of people committed to a common objective.

Although all these are great advantages picturing a bright future of the education system under the upcoming years of technical modernity we must not be naive and think that all these things can happen without a strong technological basis in form of access to proper facilities and advanced IT and social media instruction and assistance for learners and teachers; at the same, none of this is possible in the absence of institutional innovation and a fresh mindset that embraces the integration of social media with conservative learning techniques. Therefore we highly encourage the full acknowledgement of these impediments and further research into covering the gap of misperceptions and uncertainties regarding Learning 2.0 strategies and being concretely able to transform all of their opportunities and advantages into strong-stating facts.

\section{References}

Alexander, B. (2006). Web 2.0: a new wave of innovation for teaching and learning?. Educause Review. Vol. 41, No. 2, 32-44, ISSN 1479-4403

Augar, N. et all (2004). Teaching and Learning Online with Wikis. Accessed 28/12/2009 http://ascilite.org.au/conferences/perth04/procs/augar.html

Ballantyne, N.; Quinn, K. (2006). Informal Learning and the Social Web. Accessed 12/12/2009 http:/ / informallearning.pbwiki.com

Becta (2007). Emerging Technologies for Learning, Volume 2. British Educational Communications and Technology Agency. ISBN 1-853-79-467-8 Coventry, UK. Accesses 30/02/2010 http://www.becta.org.uk/research/emerging_technologies07.pdf 
Bruns, A. (2008). Blogs, Wikipedia, Second Life and Beyond. From Production to Produsage, Peter Lang Publishing, ISBN 978-0-8204-8867-7, New York

Chang, C.K. et all (2008). Constructing a community of practice to improve coursework activity. Computers E Education. Vol. 50, No. 1, 235-247, ISSN 0360-1315

Cramer, K.M. et all (2007). The virtual lecture hall: utilisation, effectiveness and student perceptions. British Journal of Educational Technology. Vol. 38, No.1, 106-115, ISSN 0007-1013

Ellison, N.; Wu, Y. (2008). Blogging in the Classroom: A Preliminary Exploration of Student Attitudes and Impact on Comprehension. Journal of Educational Multimedia and Hypermedia. Vol. 17, 99-122, ISSN 1055-8896

Hulme, M. (2009). Life Support: Young people's needs in a digital age. Youth Net report. Accessed 18/10/2009

http://www.youthnet.org/mediaandcampaigns/ pressreleases/hybrid-lives

Konieczny, P. (2007). Wikis and Wikipedia as a Teaching Tool. International Journal of Instructional Technology and Distance Learning. Vol. 4, No. 1, 15-34, ISSN 1550-6908

Lee, M.J.W. et all (2008). Talk the talk: Learner-generated podcasts as catalysts for knowledge creation. British Journal of Educational Technology. Vol. 39, No. 3, 501-521, ISSN 0007-1013

Mason, R.; Rennie, F. (2007). Using Web 2.0 for learning in the community. Internet and Higher Education, Vol. 10, 196-203, ISSN 0360-1315

Mason, Robert M. and Tabitha Hart. (2007). Libraries for Global Networked World: Toward New Educational and Design Strategies. Paper presented at the World Library and Information Congress, 19-23 August. Durban, South Africa. Accessed 5/03/2010 http:// archive.ifla.org/IV/ifla73/papers/158-Mason_Hart-en.pdf

O'Reilly, T. (2005). What is Web 2.0? Design Patterns and Business Models for the Next Generation of Software. Accessed 01/06/2009 http://www.oreillynet.com/ pub/a/oreilly/tim/news/2005/09/30/what-is-web-20.html

Pascu, C. (2008). An Empirical Analysis of the Creation, Use and Adoption of Social Computing Applications. IPTS Exploratory research on Social Computing, JRC Scientific and Technical Reports. Accessed 22/05/2010 http:/ /ftp.jrc.es/EURdoc/JRC46431.pdf

Redecker, C. et all (2009). Learning 2.0: The Impact of Web 2.0 Innovations on Education and Training in Europe. Final Report. JRC Scientific and Technical Reports. Accessed 19/04/2010 http://ipts.jrc.ec.europa.eu/publications/pub.cfm?id=2899

Rennie, F.; Mason, R. (2004). The Connection: Learning for the Connected Generation. Information Age Publishing, ISBN 1-59311-210-6, Greenwich, Connecticut

Tapscott, D. (2009). Grown Up Digital. How the net generation is changing your world, McGrawHill, ISBN 978-0-07-150863-6, New York

Tiwana, A. (2002). The Knowledge Management Toolkit. Orchestrating IT, Strategy and Knowledge Platforms, 2nd Edition, Prentice Hall PTR, ISBN 978-0-1300-9224-3, Upper Saddle River, NJ

Usluel, Y. K.; Mazman, S.G. (2009). Adoption of Web 2.0 tools in distance education. Procedia Social and Behavioural Sciences, Vol. 1, 818-823, ISSN 0747-5632

Wagner, E.D. (2005). Enabling Mobile Learning. Educause Review. Vol. 40, No. 3, 40-53, ISSN 1303-6521 


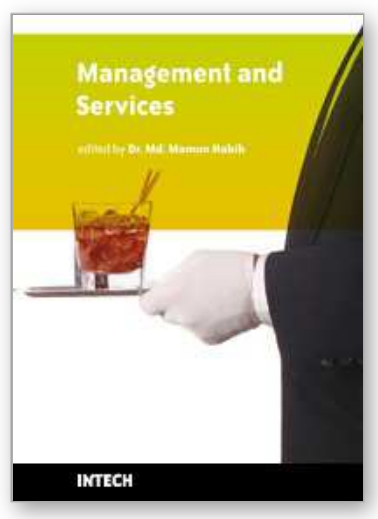

\author{
Management and Services \\ Edited by Mamun Habib
}

ISBN 978-953-307-118-3

Hard cover, 112 pages

Publisher Sciyo

Published online 06, October, 2010

Published in print edition October, 2010

Management in all business areas and organisational activities are the acts of getting people together to accomplish desired goals and objectives. Service is intangible, therefore, it is not too easy to define the theory application in varieties of service industries. Service Management usually incorporates automated systems along with skilled labour; it also provides service development. Due to enormous demand of service industries and management development, the book under the title "Management and Services" would create a milestone in management arena for all categories of readers including Business Administration, Engineering and Architecture. This book covers educational service development, service-oriented-architecture and case research analysis, including theory application in network security, GRID technology, integrated circuit application. The book is comprised of five chapters and has been divided into two parts. Part A contains chapters on service development in educational institutions and it depicts the application of supply chain management concept in service industries like tertiary educational institutions and multiple ways of web 2.0 applications transforming learning patterns and pathways. To understand the subject in a practical manner, Part B of this book consists of noteworthy case studies and research papers on management and services and represents theory application of Data mining, Fuzzy Cluster, Game theory, GRID Technology, simulation of Operational Amplifier and Current Controlled Conveyor II in network security, architecture, and integrated circuit application.

\title{
How to reference
}

In order to correctly reference this scholarly work, feel free to copy and paste the following:

Veronica Popovici and Ramona Nicoleta Bunda (2010). Learning 2.0: Collaborative Technologies Reshaping Learning Pathways, Management and Services, Mamun Habib (Ed.), ISBN: 978-953-307-118-3, InTech, Available from: http://www.intechopen.com/books/management-and-services/learning-2-0-collaborativetechnologies-reshaping-learning-pathways

\section{INTECH}

open science | open minds

\section{InTech Europe}

University Campus STeP Ri

Slavka Krautzeka 83/A

51000 Rijeka, Croatia

Phone: +385 (51) 770447

\section{InTech China}

Unit 405, Office Block, Hotel Equatorial Shanghai

No.65, Yan An Road (West), Shanghai, 200040, China

中国上海市延安西路65号上海国际贵都大饭店办公楼 405 单元

Phone: +86-21-62489820 
Fax: +385 (51) 686166

Fax: +86-21-62489821

www.intechopen.com 
(C) 2010 The Author(s). Licensee IntechOpen. This chapter is distributed under the terms of the Creative Commons Attribution-NonCommercialShareAlike-3.0 License, which permits use, distribution and reproduction for non-commercial purposes, provided the original is properly cited and derivative works building on this content are distributed under the same license. 